\title{
Prophylactic Antenatal Corticosteroid Administration before Elective Cesarean Delivery at or Near Term to Improve Perinatal Outcome
} S.A.El-Berry , M.A.Farag, A.A.Sharaf El-dine, R.I.Abdelaty and F.A.Abu El Fotouh Obstetrics and Gynecology Dept., Faculty of Medicine, Benha Univ., Benha, Egypt

E-Mail: fatmaatif1985@gmail.com.

\section{Abstract}

To evaluate whether giving the recommended prophylactic course of dexamethasone before delivery reduces the occurrence of neonatal respiratory morbidities and the need for NICU admission after elective cesarean delivery between 37 and 39 weeks. This is a randomized case control retrospective study conducted at the NICU of Benha children hospital during the period started from November 2017. It reviewed the medical record of 100 neonates delivered by elective cesarean section at the period between 37 and 39 weeks gestation after uncomplicated pregnancy and admitted to NICU due to respiratory morbidities that occur commonly after elective cesarean delivery specially TTN . The neonates were divided into 2 exposed groups whose mothers received prophylactic antenatal dexamethasone either single dose [group 2] or repeated doses [group 3], and non-exposed group [group 1] who's mothers did not receive dexamethasone. Neonatal respiratory morbidity was compared between the three groups. Data was analysed using SPSS 19.There was no significant difference between the corticosteroid exposed groups and non-exposed groups regarding admission to NICU [p= o.570], respiratory distress syndrome [no cases of RDS have been recorded], transient tachypnea of the neonate [all cases in different groups were RD due to TTN], need for mechanical ventilation [ $p=0.701$ ], final outcome, and length of hospital stay . Therefore no correlation between antenatal corticosteroid administration before elective cesarean delivery at or near term and neonatal respiratory outcome $[\mathrm{P}$ value $=0.388$ ].Prophylactic antenatal corticosteroid for elective cesarean delivery between 37 and 39 weeks is not effective in improving neonatal outcomes.

Keywords: Elective cesarean delivery, Antenatal cortices, Teroid, Neonatal respiratory distress.

\section{Introduction}

There is a rising trend towards elective Caesarean section [CS] worldwide in the past decades. The major contribution is pervious scar due to drastic decline in trial of vaginal delivery after c.s scar [ $34 \%$ points per year from 2000 to 2009].1,2 Other reasons for this increased trend are elective Caesarean for breech presentation and maternal request.

Dramatic decline in trial of scar is probably due to the fear that trial of labour would be associated with higher risk of maternal and perinatal mortality [2-3]

Neonatal Respiratory Morbidity [NRM] is one of the known complications of elective CS conducted between $37-38+6$ weeks of pregnancy. It ranges from transient tachypnoea [TTN] of newborn to respiratory failure. In 1964, the association of NRM with term elective CS was highlighted for the first time. Since then large number of studies were conducted to establish their correlation. A recently cohort study further strengthened this association [4] .

Elective term delivery by CS is responsible for $50 \%$ of potentially avoidable causes of neonatal respiratory distress [NRD].10 TTN is the most common cause of NRM followed by RDS.5 Iatrogenic RDS [after elective CS] persists as a cause of neonatal morbidity and mortality [6-7] .
When infants are delivered near or at term especially by elective caesarean delivery before the onset of spontaneous vaginal delivery, usually they are deprived of necessary hormonal changes resulting in the development respiratory complications specially neonatal distress syndrome [8].

Apart from the mode of delivery, gestational age at the time of delivery also affects risk of NRM. Number of studies 9,10 have shown that the risk of NRM is inversely proportional to the gestational age at the time of elective CS. It is $73.8 / 1000$ at $37+6$ weeks, $42.3 / 1000$ at $38+6$ weeks and $17.6 / 1000$ at $39+6$ weeks.11 This trend is particularly pronounced for RDS where the risk decreases from about $39 / 1000$ for period between $37+0$ to $37+6$ to $8 / 1000$ for period between $39+0$ to $39+6$ weeks, while TTN decreases from $7 / 1000$ at 37 to $4 / 1000>39$ weeks [12].

The development of NRD leads to chain of events, including admission to neonatal intensive care unit [NICU], affecting motherchild bonding, cost of care and complications from invasive procedures, including artificial ventilation.13 It is also associated with the development of asthma in childhood [14] .

In order to decrease this complication, guidelines issued by the American Council of Obstetricians and Gynaecologists [ACOG],15 the Royal College of Obstetricians and Gynaecologists [RCOG] and NICE 
recommend that EL-LSCS should be planned at 39+0 weeks.

If EL-LSCS is deemed necessary prior to 39 weeks, prophylactic dexamethasone at least 48 hours prior to the date of CS will decrease the risk of NRM.16 However, the evidence for such recommendation is questionable. Studies have shown no additional benefits of administering corticosteroids to mothers after 34 weeks [17].

They have explained this as corticosteroids play an important role in final maturation of lungs by increasing number and function of sodium $[\mathrm{Na}]+$ channels and increasing production of surfactant.

While there is strong evidence that a single antenatal prophylactic course of corticosteroids in preterm labor before 34 weeks gestation is effective in neonatal death, RDS, cerebroventricular hemorrhage, necrotizingenterocolitis, and admission to a neonatal intensive care and respiratory support [18]. The question is whether these benefits might actually extend to 37 and 38 weeks.

The ASTEC trial has proven that incidence of respiratory distress at 37-39 weeks of gestation are reduced to half with the use of antenatal steroids, TTN decreases from $4 \%$ to $2.1 \%$ and RDS from $1 \%$ to $0.2 \%$. This trial also showed that there is 6-fold decrease in the rate of NICU admission with NRD after giving antenatal corticosteroids [19].

The decreased incidence of TTN in steroid group is based on normal physiology during labour. During labour there is a rise in corticosteroids' level which encourages the expression of the epithelial channel gene and allows the lung to switch from fluid secretion to fluid absorption. ELSCS bypasses this mechanism, thereby predisposing to the increased risk of NRM [20].

There are a number of studies 16,21 that have proven that single course of antenatal corticosteroids is not associated with maternal/foetal infection and has no adverse effects on neurological or cognitive system of the neonate.

The evidence for administration of corticosteroids after 34 weeks is still controversial since there is a lack of properly conducted trials of antenatal corticosteroids in mothers delivered by elective cesarean delivery at this gestational age.

The current study was planned to compare incidence and pattern of NRM in neonates delivered by planned CS between $37-38+6$ weeks after prophylactic dexamethasone to mothers with those who delivered without prophylactic dexamethasone.

\section{Subjects and methods}

The randomized case control study was conducted in the NICU of Benha children hospital and Ob./ Gyn. Department of Qwesna central hospital during the period started from November 2017 to November 2019 . The protocol of the study was approved by the Research Committee of the Hospital. It included 100 neonates who were delivered by EL-LSCS between 37 to $38+6$ weeks of pregnancy after uncomplicated pregnancy and admitted to NICU due to respiratory problems that occurs commonly after elective cesarean delivery specially TTN. Neonates with history of antenatal diabetes mellitus [DM] [gestational or overt diabetes], history of rupture of membranes, history of drug intake or any chronic medical illness ,infections including tuberculosis, congenital anomalous fetus and intrauterine growth restriction [IUGR] fetuses were excluded.

Patients were divided according to antenatal maternal steroid administration and its dose protocol into 2 exposed groups who's mothers received prophylactic antenatal dexamethasone either single dose [group 2] or repeated doses [group 3], and non-exposed group [group 1] who's mothers did not receive dexamethasone. Neonatal medical records were reviewed with full antenatal history taking from their mothers and all required information was documented in a structured Performa whose primary outcome measure was to see the number of babies with NRM in each group and secondary outcome measure was to compare difference in nursery admission and total hospital stay in different groups. TTN/RDS were diagnosed by neonatologist on the basis of clinical features and radiological findings. Data was analysed using SPSS 19. Baseline characteristics were compared using means and standard deviations [SD] and proportions of both groups by student's $t$ test and Chi-square respectively. Factors associated with TTN were explored through student's t-test, Fisher exact and chisquare tests whichever was appropriate.

\section{Results}

The 100 neonates included in this study 43 of them are group 1 [non exposed group] ,49 group 2[with single steroid course] and 8 group 3[with multiple steroid courses].The three groups were comparable regarding the baseline characteristics There were no significant differences between studied groups regarding baseline characteristics [ maternal age, parity, gestational age, indications for CS , type of anesthesia, neonatal gender\& birth weight ] Table [1]. 
Most common indication of C-section was abdominal scar due to previous C-section. As regarding type of anesthesia during CS it was spinal in 99 and general in 1 of the whole cases of our studied groups.

Table (1) Baseline characteristics of the studied groups.

\begin{tabular}{|c|c|c|c|c|c|}
\hline & $\begin{array}{c}\text { Group 1 } \\
\text { [no steroid] } \\
\text { No= }=43[\%]\end{array}$ & $\begin{array}{c}\text { Group } 2 \\
\text { [single course] } \\
\text { No= } 49[\%]\end{array}$ & $\begin{array}{c}\text { Group } 3 \\
{[2 \text { courses] }} \\
\text { No=8[\%] }\end{array}$ & Test & $P$ value \\
\hline $\begin{array}{l}\text { Age }[\text { years] } \\
{[\text { mean } \pm \text { SD] }} \\
\text { Range }\end{array}$ & $\begin{array}{c}28.4 \pm 4.5 \\
{[20-37]}\end{array}$ & $\begin{array}{c}26.18 \pm 4.08 \\
{[20-35]}\end{array}$ & $\begin{array}{c}26.81 \pm 2.92 \\
{[24-33]}\end{array}$ & $\begin{array}{c}\mathrm{F} \text { test }= \\
2.806\end{array}$ & 0.083 \\
\hline $\begin{array}{l}\text { parity } \\
\text { primi-gravida } \\
\text { multi-gravida }\end{array}$ & $\begin{array}{c}6[14] \\
37[86]\end{array}$ & $\begin{array}{c}4[8.2] \\
45[91.8]\end{array}$ & $\begin{array}{c}0[0] \\
8[100]\end{array}$ & $1.806^{*}$ & 0.403 \\
\hline $\begin{array}{l}\text { Gestational } \\
\text { age[weeks] } \\
{[\text { mean } \pm \text { SD] }}\end{array}$ & $\begin{array}{c}38.1 \pm 5 d \\
{[37-38+6]}\end{array}$ & $\begin{array}{c}37.8 \pm 4 d \\
{[37-38+6]}\end{array}$ & $\begin{array}{c}38.4 \pm 6 d \\
{[37-38+6]}\end{array}$ & $\begin{array}{l}\mathrm{F} \text { test } \\
2.214\end{array}$ & 0.141 \\
\hline $\begin{array}{l}\text { Range } \\
\text { Indication of CS }\end{array}$ & & & & & \\
\hline 1ry infertility & $1[2.3 \%]$ & $0[0 \%]$ & $0[0 \%]$ & & \\
\hline $\mathrm{ECS}[\mathrm{CPD}]$ & $2[4.7 \%]$ & $4[8.2 \%]$ & $0[0 \%]$ & 6.412 & 0.372 \\
\hline ECS[old age] & $3[7 \%]$ & $0[0 \%]$ & $0[0 \%]$ & & \\
\hline $\begin{array}{l}\text { CS scar } \\
\text { Type of } \\
\text { anaesthesia }\end{array}$ & $37[86 \%]$ & $45[91.8 \%]$ & $8[100 \%]$ & & \\
\hline $\begin{array}{l}\text { General } \\
\text { spinal }\end{array}$ & $\begin{array}{c}0[0 \%] \\
43[100 \%]\end{array}$ & $\begin{array}{c}1[2 \%] \\
48[98 \%]\end{array}$ & $\begin{array}{c}0[0 \%] \\
8[100 \%]\end{array}$ & 1.246 & 0.591 \\
\hline $\begin{array}{l}\text { Gender: } \\
\text { female } \\
\text { male }\end{array}$ & $\begin{array}{l}10[23.3 \%] \\
33[76.7 \%]\end{array}$ & $\begin{array}{l}15[30.4 \%] \\
34[69.6 \%]\end{array}$ & $\begin{array}{l}2[25 \%] \\
6[75 \%]\end{array}$ & 0.647 & 0.572 \\
\hline $\begin{array}{l}\text { Post- delivery } \\
\text { weight: } \\
{[\text { mean } \pm \text { SD] }} \\
\text { Range }\end{array}$ & $\begin{array}{c}3283.2 \pm 337.2 \\
{[2700-4100]}\end{array}$ & $\begin{array}{c}3210.1 \pm 356.4 \\
{[2700-4200]}\end{array}$ & $\begin{array}{c}3188.2 \pm 317.4 \\
{[2800-3700]}\end{array}$ & $\begin{array}{c}\text { F Test }^{=} \\
0.620\end{array}$ & 0.410 \\
\hline
\end{tabular}

The number of neonates being admitted to NICU with respiratory morbidities after elective CS was slightly lower in group1 [no corticosteroid] when compared to group $2 \&$ 3 [corticosteroid exposed groups] [43\% vs. $57 \%$ respectively from the total number of the studied $100 \quad$ neonates].Antenatal administration of dexamethasone was not associated with reduction in the risk of neonatal admission to PCBU. Table (2).

All neonates were admitted by RD of different grades due to transient tachypnea of newborn . No cases of RDS was recorded between studied cases. Therefore no statistically significant difference between the studied groups with regard to cause of NICU admission [P value o.570] and the risk of neonatal RDS after elective CS at term. Table (2).

There was no significant difference between different groups regarding rate of need for mechanical ventilation [4[9.8\%]in group $1,4[8.2 \%]$ in group $2 \& 0[0 \%]$ in group $3][\mathrm{P}$ value 0.701$]$. One neonate of all cases died because of pneumothorax as a complication during application of CVP line, 3 complicated by sepsis \& rest of all babies were discharged home. In all groups, majority of babies remained in NICU for less than 48 hours .

There was no statistically significant difference between studied groups with regard to final outcome, requirement for mechanical ventilation and length of hospital stay Table [2].

Therefore no correlation between antenatal corticosteroid administration before elective cesarean delivery at or near term and neonatal respiratory outcome $[\mathrm{R}=0.087, \mathrm{P}$ value $=0.388]$. Table (3). 
Table (2) Comparison between the studied groups according to usage of antenatal steroids regarding neonatal outcome.

\begin{tabular}{|c|c|c|c|c|c|}
\hline & $\begin{array}{c}\text { Group 1 } \\
\text { [no } \\
\text { steroid] } \\
\text { No }=43\end{array}$ & $\begin{array}{c}\text { Group } 2 \\
\text { [single } \\
\text { course] } \\
\text { No=49 }\end{array}$ & $\begin{array}{c}\text { Group } 3 \\
{\left[\begin{array}{c}2 \text { courses }] \\
\text { No=8 }\end{array}\right.}\end{array}$ & Fisher Exact test & $P$ value \\
\hline Causes of & & & & 0.797 & 0.570 \\
\hline NICU & $4[9.3 \%]$ & $4[8.2 \%]$ & $0[0 \%]$ & & \\
\hline $\begin{array}{l}\text { admission } \\
\text { malignant TTN }\end{array}$ & $39[90.7 \%]$ & 45 [91.8\%] & $8[100 \%]$ & & \\
\hline TTN & & & & & \\
\hline V support & & & & & \\
\hline No & $39[90.2 \%]$ & 45 [91.8\%] & $8[100 \%]$ & 2.246 & 0.701 \\
\hline yes & $4[9.8 \%]$ & $4[8.2 \%]$ & $0[0 \%]$ & & \\
\hline Hospital stay & & & & 23.254 & 0.401 \\
\hline$<6 \mathbf{h}$ & $15[34.8 \%]$ & $16[32.6 \%]$ & $5[62.5 \%]$ & & \\
\hline $6-48 h$ & $14[32.5 \%]$ & $14[28.5 \%]$ & $2[25 \%]$ & & \\
\hline$>48 h$ & $14[32.5 \%]$ & $19[38.7 \%]$ & $1[12.5 \%]$ & & \\
\hline Fetal outcome: & & & & 4.321 & 0.362 \\
\hline Discharge & $43[100 \%]$ & $45[91.8 \%]$ & $8[100 \%]$ & & \\
\hline Sepsis & $0[0 \%]$ & $3[6.1 \%]$ & $0[0 \%]$ & & \\
\hline died & $0[0 \%]$ & $1[2.1 \%]$ & $0[0 \%]$ & & \\
\hline
\end{tabular}

Table (3) Correlation between antenatal steroid use and fetal outcome.

\begin{tabular}{lll}
\hline Parameter & R & P value \\
\hline Steroid use & 0.087 & 0.388 \\
\hline
\end{tabular}

\section{Discussion}

The increase in elective CS rates in the past decades has highlighted the need to reduce respiratory complications associated with this high rate of CS. In developing countries resources are scarce and it is difficult to provide expensive treatment as neonatal care. This leads to financial burden on the state as well as the individual in the form of expensive neonatal care, parental anxiety, separation of newborn from the mother and increased risk of neonatal morbidity secondary to NICU admission.

Overall incidence of NRD is estimated at $2.8 \%$ and the main risk factors are gestational age at the time of delivery and mode of delivery [2].

There is 4-fold increase in respiratory distress and 5-fold increased risk of serious respiratory morbidity in EL-LSCS compared to vaginal delivery.4 Although at term, risk of NRM is low [2-fold] but not negligible, therefore it is important to take best possible action to decrease this complication.

In the absence of stress of labour there is lack of catecholamines and corticosteroids release which is mandatory for final maturation of fetal lungs. Basically there are two mechanisms required to ensure neonatal lung maturity at term: elimination of excessive fluid from alveoli; and increase in pulmonary blood perfusion.

Recent evidence indicates that apart from traditional mechanical concept of vaginal squeeze, molecular mechanism predominantly lung, $\mathrm{Na}+$ channels promote alveolar fluid drainage and these channels may be underactive in fetuses not exposed to the process of labour.8 The expression of these channels is regulated by several factors such as endogenous catecholamines, oxygen, thyroid hormones and, finally, by glucocorticoids. Among these, the most important factor for induction of $\mathrm{Na}$ reabsorption in the foetal lungs and surfactant production in advanced gestational age are catecholamines and glucocorticoids. Glucocorticoids increase the number and function of these $\mathrm{Na}+$ channels as well as responsiveness to catecholamines and thyroid hormones, providing rationale for their exogenous administration in cases of ELLSCS.

In the current study, the effects of administering corticosteroids to mothers who were planned to have elective C-section after 37 weeks gestation, were evaluated in terms of neonatal respiratory morbidity requiring oxygen supplementation and the requirement for admission to NICU. 
Neonatal respiratory morbidity is increased by various risk factors including gender of the newborn, birth weight, type of anesthesia given to mother at the time of $\mathrm{C}$-section, maternal medical conditions like premature rupture of membranes [PROM], maternal fever, and history of maternal medication use.22,23 But in this study, all those babies who were born to mothers with history of PROM and other medical disorders were excluded. All the Csections except one c.s were performed under spinal anesthesia. There was no statistically significant difference between the different groups in our study as far as birth weight and gender of the neonates were concerned.

The result of the present study showed no significant relationship of dexamethasone with NRM i.e revealed no beneficial effect of antenatal administration of steroids for parturients scheduled for elective cesarean delivery between 37 and 39 weeks of gestation regarding reduction of respiratory morbidity, NICU admission or need for mechanical ventilation. All neonates were admitted to NICU with RD due to TTN and the number of babies admitted in nursery with respiratory distress was higher in dexamethasone exposed Groups [2+ 3] than non exposed Group[1] $[57 \%$ vs. $43 \%$ respectively from the total number of the studied 100 neonates].

The result of the present study coming in agreement with a study carried out by Hutchson, who showed that antenatal corticosteroids have no role in reducing the neonatal respiratory morbidity as well as NICU admission.20 $\mathrm{He}$ has found that the total number of babies admitted in the betamethasone group was 26/467 and in the control group 32/475, with no statistically significant difference in the overall rate of admissions to PCBU [24].

A study of 362 neonates born at 34 weeks of gestation or more found that even if immature fetal lung indices were detected, administration of antenatal corticosteroids did not reduce respiratory morbidity in neonates born at 34 weeks of gestation or more [17].

A recent trial published similar results showing that conclusions antenatal treatment with corticosteroids at 34-36 weeks of pregnancy does not reduce the incidence of respiratory disorders in newborn infants [25] .

Although the previous 3 studies focused on a different gestational age from that of the present study, still a great similarity occurs between both studies and the mechanism of Steroid action after 34 weeks either late preterm [34-36+6] or early term[37-38+6] the same.
On the contrary to our study; The Antenatal Steroids for Term Elective Cesarean Section study, by Stutchfield et al, examined the use of antenatal corticosteroids given to women who planned to deliver at 37 weeks of gestation or greater by elective cesarean. Although the investigators found a significant difference in the rate of RDS between the treatment and control groups [1.1 and $0.2 \%$, respectively], they had similar numbers of admissions to neonatal intensive care for both groups [26 and 32, respectively], indicating that although antenatal corticosteroids may have decreased the incidence of respiratory morbidity, other neonatal morbidities still necessitated intensive care.

Also the data presented by Stutchfield et al show that delaying non-urgent elective caesarean section until 39 weeks is much more effective in avoiding neonatal admission than giving steroids. For the $15 \%$ or so of such women who will go into labour between 37 and 39 weeks, the inconvenience of having their caesarean "out of hours" is likely to be less than that of having their baby admitted to special care. Most will only be in early labour, avoiding the complications of an acute intrapartum emergency [19] .

Betamethasone given before elective caesarean section at term reduces respiratory distress and admission to a special care baby unit [26]. The benefit falls with increasing gestation, supporting the recommendation to delay elective caesarean section until the 39th week. Nevertheless, the benefits of antenatal steroids persist till 39 weeks [27].

Many other studies are also in agreement with a Cochrane systematic review 2009 which is in contrast with our current study and stated that there was a reduction in NICU admission for babies whose mothers received antenatal corticosteroids.26 However, the same review did not find any statistically significant difference as far as the respiratory morbidity was concerned.

Other recent studies [28],[29],[30],[31],[32] with the most recent update of Cochrane Systematic Reviews [33] concluded that Steroid cover significantly reduced the risk of respiratory morbidity and admission to NICU in babies delivered by elective cesarean section between 37-39 weeks. However, the authors described the quality of evidence, was low and very low for the outcomes of RDS, TTN and admission to NICU for respiratory morbidity, indicating that the true effect could potentially be substantially different from the found estimate of effect. Also the unblinded design of the studies[as no placebo was used in 3 of the 4 
trials ] elevating the risk of bias. Lack of blinding in randomized studies can potentially predispose to some exaggeration of the intervention effects for some outcomes [1].

Finally Our study continues to support the notion that gestational maturity itself has the strongest correlation with a lack of neonatal morbidity. So delaying delivery until 39 weeks, unless necessary, would seem a more prudent option than giving steroids whose long term safety, even as a single course, remains questionable.

\section{References}

[1] J.Villar, E.Valladares, D.Wojdyla, N.Zavaleta, G.Carroli, A.Velazco, Caesarean delivery rates and pregnancy outcomes: the 2005 WHO global survey on maternal and perinatal health in Latin America. Lancet ,Vol. 367, PP.1819-29, 2006

[2] S.Paganelli, E.Soncini, G.Gargano, F.Capodanno,C.Vezzani, GB.La Sala, Retrospective analysis on the efficacy of corticosteroid prophylaxis prior to elective caesarean section to reduce neonatal respiratory complications at term of pregnancy: review of literature. Arch Gynecol Obstet, Vol. 288, PP.1223-9, 2013

[3] GC.Smith, JP.Pell, AD.Cameron, R.Dobbie, Risk of perinatal death associated with labor after previous cesarean delivery in uncomplicated term pregnancies. JAMA, Vol.287,pp2684-90, 2002

[4] AK.Hansen, K.Wisborg, N.Uldbjerg, TB.Henriksen, Risk of respiratory morbidity in term infants delivered by electivecaesarean section: cohort study. BMJ, Vol.336,pp85-99. 2008

[5] CL.Hermansen, KN.Lorah. Respiratory distress in the newborn. Am Fam Physician,Vol.76,pp .987-94, 2007

[6] SB.Ainsworth, Pathophysiology of neonatal respiratory distress syndrome: implications for early treatment strategies. Treat Respir Med,Vol.4, PP.423-37, 2005

[7] CJ.Louis, EC.Eichenward, AR.Stark, Manual of neonatal care. 5th ed. Philadelphia :LippincottWilliams andWilkins,Vol.25, PP.60-99, 2004.

[8] L.Jain, DC.Eaton. Physiology of fetal lung fluid clearance and the effect of labor. Semin Perinatol., Vol.30, PP.34-40,2006

[9] ATN.Tita, MB.Landon, CY.Spong, Y.Lai, Timing of elective repeat cesarean delivery at term and neonatal outcomes. $\mathrm{N}$ Engl J Med, Vol.360, PP.111-20,2009
[10] W.Yee, H.Amin, S.Wood, Elective cesarean delivery, neonatal intensive care unit admission, and neonatal respiratory distress. Obstet Gynecol,Vol.111, PP.8238,2008

[11] PNB. David, ML. uesley, Antepartum Haemorhage. Evidence- based text for MRCOG. 2nd ed: Edward: Arnold, Vol.37, PP. PP.315-28,2010.

[12] V.Zanardo, AK.Simbi, M.Franzoi, G.Solda, Neonatal respiratory morbidity risk and mode of delivery at term: influence of timing of elective caesarean delivery. Acta Pediatr, Vol.93, PP.6437,2004

[13] J.Madar, S.Richmond, E.Hey, Surfactant deficient respiratory distress after elective delivery at 'term'. Acta Paediatr, Vol.88, PP.1244-8,1999.

[14] GCS.Smith, AM.Wood, IR.White, JP.Pell, AD.Cameron, R.Dobbie Neonatal respiratory morbidity at term and the risk of childhood asthma. Arch Dis Childhood., Vol.89, PP.956-60,2004

[15] Clinical Practice Guidelines for Perinatal Care. American College of Obstetrics and Gynaecology [online] [cited 2014 May 5]; Available from URL: https://www.wellcare.com/wcassets/corpo rate/ assets/ny_medicaid_pem_cpg perinatalcare.pdf.

[16] Royal College of Obstetricians and Gynaecologists Scientific Advisory Committee. RCOG guidelines No 7: antenatal corticosteroids to prevent respiratory distress syndrome. 2nd ed. London: RCOG Press, Vol.39, PP.227230,2004.

[17] BD.Kamath-Rayne, EA.DeFranco, MP.Marcotte, Antenatal steroids for treatment of fetal lung immaturity after 34 weeks of gestation: an evaluation of neonatal outcomes. Obstet Gynecol; Vol.119, PP.909-916,2012.

[18] D.Roberts, SR.Dalziel, Antenatal corticosteroids for accelerating fetal lung maturation for women at risk of preterm birth. Cochrane Database Syst Rev, Vol.79, PP.44-54,2006.

[19] P.Stutchfield, R.Whitaker, I.Russell. Antenatal betamethasone and incidence of neonatal respiratory distress after elective caesarean section: pragmatic randomised trial. BMJ;Vol.33, PP.662-665,2005

[20] HM.O'Brodovich, Immature epithelial $\mathrm{Na}+$ channel expression is one of the pathogenetic mechanisms leading to human neonatal respiratory distress syndrome.Proc Assoc Am Physicians, Vol.108, PP.345-55,1996 
[21] P.Crowley, Prophylactic corticosteroids for preterm birth. Cochrane Database Syst Rev, Vol.32[2], PP. 65-70, 2000.

[22] A.Berg, RM.van Elburg, HP.van Geijn, WP.Fetter. Neonatal respiratory morbidity following elective caesarean section in term infants. A 5-year retrospective study and a review of the literature. Eur J Obstet Gynecol Reprod Biol,Vol.98, PP.9$13,2001$.

[23] KA.Gerten, DV.Coonrod, RC.Bay, LR.Chambliss, Cesarean delivery and respiratory distress syndrome: does labor make a difference? Am J Obstet Gynecol, Vol.193, PP.1061-4, 2005

[24] D.Hutchon, A clearer explanation of no benefit for steroids. BMJ e-letter, Vol.8, PP.12-15,2005.

[25] A.M.Porto, I.C.Coutinho, J.B.Correia , Effectiveness of antenatal corticosteroids in reducing respiratory disorders in late preterm infants: Randomised Clinical Trial. BMJ, Vol.342, PP. 16-96, 2011.

[26] Sotiriadis, G.Makrydimas, S. Papatheodorou, Ioannidis JP. Corticosteroids for preventing neonatal respiratory morbidity after elective caesarean section at term. Cochrane Database Syst ,Vol.4, PP.267-270,2009.

[27] J.J.Morrison, JM.Rennie, PJ.Milton, Neonatal respiratory morbidity and mode of delivery at term: influence of timing of elective caesarean section. British Journal of Obstetrics and Gynecology Vol.102[2], PP.101-6,1995.

[28] A.Khushdil, S.Baqai, M.Ahmed and Z.Ahmed , Role of Corticosteroids in Reducing Respiratory Morbidity in Neonates Delivered by Elective Cesarean
Section before 39 Weeks. Journal of the College of Physicians and Surgeons Pakistan, Vol. 28 [12], PP.906-909,2018.

[29] A.Dileep, NB.Khan, SS.Sheikh, Comparing neonatal respiratory morbidity in neonates delivered at term by elective Caesarean section with and without dexamethasone: retrospective cohort study. J Pak Med Assoc, Vol. 65, PP.60711,2015

[30] MR.Ahmed, W.Ali, S.Ahmed, Antenatal steroids at 37 weeks, does it reduce neonatal respiratory morbidity? A randomized trial. J Matern Fetal Neonatal Med,Vol.28, PP.148-690, 2015

[31] AM.Nada, MM.Shafeek, MA.El Maraghy, AH.Nageeb, Antenatal corticosteroid administration before elective caesarean section at term to prevent neonatal respiratory morbidity: a randomized controlled trial. Eur J Obstet Gynecol Reprod Biol,Vol.199, PP.88-91,2016.

[32] AM.Nooh, HM.Abdeldayem, E.Arafa, SA.Shazly, H.Elsayed, WA.Mokhtar, Does implementing a regime of dexamethasone before planned cesarean section at term reduce admission with respiratory morbidity to neonatal intensive care unit? A randomized controlled trial. Journal of Maternal-Fetal \& Neonatal Medicine,Vol.31[5], PP.614-20, 2018.

[33] A.Sotiriadis, G.Makrydimas, S. Papatheodorou, Corticosteroids for preventing neonatal respiratory morbidity after elective caesarean section at term. Cochrane Database of Systematic Reviews ,Vol.59, PP.247-250,2018. 